\title{
Presença de resíduos de antibióticos em leite bovino pasteurizado
}

\author{
Presence of antimicrobial residues in commercialized pasteurized bovine milk
}

Christina Maria Queiroz de Jesus MORAIS ${ }^{1 *}$, Thiago dos Santos DURÃES ${ }^{1}$, Armi Wanderley da NÓBREGA ${ }^{1}$, Silvana do Couto JACOB ${ }^{1}$

\begin{abstract}
Resumo
O objetivo deste trabalho foi avaliar a presença de resíduos de antibióticos no leite bovino pasteurizado comercializado na cidade do Rio de Janeiro e propor um programa de monitoramento à Vigilância Sanitária Municipal com base nesses dados. Durante o período de abril a agosto de 2006 foram analisadas 57 amostras de leite através de ensaios imunoenzimáticos para análise qualitativa dos betalactâmicos, tetraciclinas e estreptomicina/diidroestreptomicina na forma de kits. Os resultados evidenciaram que os antimicrobianos continuam sendo utilizados no tratamento do gado leiteiro.
\end{abstract}

Palavras-chave: drogas veterinárias; monitoramento; métodos de triagem.

\begin{abstract}
The aim of this work was to evaluate the antimicrobial residues present in pasteurized milk commercialized in the city of Rio de Janeiro Brazil and to suggest a monitoring program based on these data. During the period from April to August 2006, 57 milk samples were analyzed through and enzyme immunoassays for the qualitative analysis of beta-lactams, tetracyclines, and streptomycin/dihydrostreptomycin test Kits. The results showed that the studied antibiotics are have been used for the treatment of the dairy cattle.

Keywords: veterinary drugs; monitoring; screening methods.
\end{abstract}

\section{Introdução}

A presença de resíduos de antibióticos no leite interfere na fabricação de alguns produtos lácteos, podendo ocasionar no homem reações alérgicas, além de resistência à antibioticoterapia (FONSECA; SANTOS, 2000). Várias drogas são empregadas no gado leiteiro com o objetivo profilático, na tentativa de evitar a mastite, tais como antimicrobianos, antiparasitários e antiinflamatórios não esteroidais. Quando o período de carência, a dosagem e a via de administração destes antibióticos são desrespeitados, ocorre a presença de resíduos de antibióticos indesejáveis nos alimentos de origem animal, acarretando risco à saúde humana (PONTES NETTO et al., 2005).

A avaliação da exposição da população a resíduos de antibióticos é de vital importância para nortear as ações de controle sanitário visando à proteção do consumidor. Neste trabalho avaliou-se a qualidade de 57 amostras de leite pasteurizado dos tipos B e C obtidas no comércio varejista da cidade do Rio de Janeiro.

Kits para ensaios imunoenzimáticos foram utilizados para a análise qualitativa dos betalactâmicos, tetraciclinas e estreptomicina/diidroestreptomicina nas amostras de leite bovino. Esses kits, também conhecidos como testes de triagem, possuem métodos rápidos e práticos e são largamente utilizados como instrumento para prevenção de riscos para a saúde pública, devido à sua sensibilidade, especificidade, rapidez e baixo custo (TRULLOLS; RUISÀNCHEZ; RIUS, 2004).

Um programa de monitoramento baseia-se na integração dos métodos de triagem e confirmação, já que nenhum teste isolado atende a todos os requisitos analíticos requeridos (HILL; REYNOLDS, 1999; VACÁRCEL, 1999). Esses métodos devem ser usados na definição de uma estratégia de monitoramento, na qual a análise cromatográfica seja realizada apenas em amostras positivas e, consequentemente, reduzindo substancialmente o custo do monitoramento por análise cromatográfica. Para uma melhor qualidade do leite destinado à população, deve-se escolher um plano eficiente de amostragem e kits sensíveis aos contaminantes de interesse, com limites de detecção abaixo dos limites máximos de resíduos permitidos pela legislação brasileira vigente (ANVISA, 2003), elaborar métodos de análise integrando triagem e confirmação e ter conhecimento da interpretação dos resultados para que medidas legais possam ser tomadas pelos órgãos competentes com vistas à segurança alimentar.

Recebido para publicação em 14/1/2008

Aceito para publicação em 7/7/2009 (003115)

${ }^{1}$ Instituto Nacional de Controle de Qualidade em Saúde - FIOCRUZ, Av. Brasil, 4365, Manguinhos, CEP 21045-900, Rio de Janeiro - RJ, Brasil,

E-mail: christina.morais@incqs.fiocruz.br

${ }^{*}$ A quem a correspondência deve ser enviada 